\title{
Corrigendum: New Insights Into the Plastome Evolution of the Millettioid/Phaseoloid Clade (Papilionoideae, Leguminosae)
}

\author{
Oyetola Oyebanji ${ }^{1,2}$, Rong Zhang ${ }^{1}$, Si-Yun Chen ${ }^{1}$ and Ting-Shuang $Y i^{1 *}$ \\ ${ }^{1}$ Germplasm Bank of Wild Species, Kunming Institute of Botany, Chinese Academy of Sciences, Kunming, China, ${ }^{2}$ Kunming \\ College of Life Science, University of Chinese Academy of Sciences, Beijing, China
}

Keywords: evolutionary relationships, inversion, IR expansion/contraction, Leguminosae, Plastome, the Millettioid/Phaseoloid clade

\section{A Corrigendum on}

New Insights Into the Plastome Evolution of the Millettioid/Phaseoloid Clade (Papilionoideae, Leguminosae)

by Oyebanji, O., Zhang, R., Chen, S.-Y., and Yi, T.-S. (2020). Front. Plant Sci. 11:151. doi: $10.3389 / f p l s .2020 .00151$

In the original article, there was a mistake in the legend for Table 1 as published. The use of " $C$. gracilis" in the ${ }^{\mathrm{h}}$ legend is incorrect. The correct legend appears below.

"h Duplicated in the IR of all species except D. araripensis, L. domingensis, O. pinnata, P. violacea, X. stuhlmannii, I. linifolia and tinctoria."

\section{OPEN ACCESS}

Approved by:

Frontiers Editorial Office,

Frontiers Media SA, Switzerland

*Correspondence:

Ting-Shuang $Y$

tingshuangyi@mail.kib.ac.cn

Specialty section:

This article was submitted to Plant Systematics and Evolution,

a section of the journal

Frontiers in Plant Science

Received: 12 January 2021 Accepted: 18 January 2021

Published: 01 March 2021

Citation:

Oyebanji O, Zhang R, Chen S-Y and Yi T-S (2021) Corrigendum: New Insights Into the Plastome Evolution of the Millettioid/Phaseoloid Clade (Papilionoideae, Leguminosae).

Front. Plant Sci. 12:652483. doi: 10.3389/fp/s.2021.652483
In the original article, there was a mistake in Figure $\mathbf{1}$ and $\mathbf{4}$ as published. The mistakes were: Cochlianthus gracilis (Phaseoleae), Craspedolobium schochii (Millettieae), and Shuteria vestita (Desmodieae). The corrected taxonomic names appear below.

Inserted CORRECTED names: Philenoptera violacea (Millettieae), Spatholobus sp. (Phaseoleae), and Shuteria vestita (Phaseoleae), respectively.

In the original article, there was a mistake in Supplementary Figure S1 as published. The mistakes were: Cochlianthus gracilis and Craspedolobium schochii.

Inserted CORRECTED names: Philenoptera violacea and Spatholobus sp. respectively.

In the original article, there was a mistake in Supplementary Figure S2 as published. The mistakes were: Cochlianthus gracilis and Craspedolobium schochii.

Inserted CORRECTED names: Philenoptera violacea and Spatholobus sp., respectively.

In the original article, there was a mistake in Supplementary Figure S3 as published. The mistakes were: Cochlianthus gracilis and Craspedolobium schochii.

Inserted CORRECTED names: Philenoptera violacea and Spatholobus sp., respectively.

In the original article, there was a mistake in Supplementary Table S1 as published. The mistakes were: Cochlianthus gracilis and Craspedolobium schochii.

Inserted CORRECTED names: Philenoptera violacea and Spatholobus sp. have been inserted to replace the initial names respectively.

In the original article, there was a mistake in Supplementary Table S2 as published. The mistakes were: Cochlianthus gracilis (Phaseoleae), Craspedolobium schochii (Millettieae), and Shuteria vestita (Desmodieae).

Inserted CORRECTED names: Philenoptera violacea (Millettieae), Spatholobus sp. (Phaseoleae), and Shuteria vestita (Phaseoleae), respectively. 
In the original article, there was an error: The mean plastome coverage ranged between $162.0 \times$ (Cochlianthus gracilis Benth., Phaseoleae) and 1,536.4 $\times$ [Cajanus crassus (Prain ex King) Maesen, Phaseoleae]. A correction has been made to Section: Results, Sub-section- Plastome Organization and Size.

Inserted CORRECTED paragraph: The mean plastome coverage ranged between $162.0 \times$ (Philenoptera violacea (Klotzsch) Schrire, Millettieae) and 1,536.4 $\times$ [Cajanus crassus (Prain ex King) Maesen, Phaseoleae].

In the original article, there was an error: C. gracilis. A correction has been made to Section: Results, Sub-section Plastome Structural Variations in the MP Clade.

Inserted CORRECTED paragraph: $P$. violacea.

In the original article, there was an error: However, the lineage consisting of Butea monosperma (Lam.) Kuntze and Craspedolobium schochii Harms has different phylogenetic position in trees of CP and NCDs, and that of CDs, but both relationships were weakly supported. Also, the tribe Desmodieae was weakly supported to be monophyletic in CDs, but being weakly supported to be paraphyletic in CP and NCDs. The tribe Indigofereae was strongly supported as sister to the remainder of the MP clade ( $\mathrm{BS}=100 \%$, and $\mathrm{PP}=1.0$ ). Based on the current sampling, it is not sure if the tribe Desmodieae is monophyletic, while the tribes Millettieae and Phaseoleae appear non-monophyletic. correction has been made to Section: Results, Sub-section Phylogenetic Relationships of the MP Clade.

Inserted CORRECTED paragraph: However, the lineage consisting of Butea monosperma (Lam.) Kuntze and Spatholobus Hassk sp. has different phylogenetic position in trees of CP and
NCDs, and that of CDs, but both relationships were weakly supported. Also, the tribe Desmodieae was weakly supported to be monophyletic in CP and NCDs data matrices whereas strongly supported by CDs data. The tribe Indigofereae was strongly supported as sister to the remainder of the MP clade (BS $=100 \%$, and $\mathrm{PP}=1.0$ ). Based on the current sampling, it is not sure if the tribe Desmodieae is monophyletic, while the tribes Millettieae and Phaseoleae appear non-monophyletic.

In the original article, there was an error: According to this study, with the exception of the loss of the $c l p P$ introns 1 and 2 in a single species of $S$. vestita (Desmodieae) and the loss of $n d h A$ and $n d h B$ intron 1 in a single species of $L$. domingensis (Millettieae), two other introns (rps16 and rps12) have experienced multiple independent loss during the plastome evolution of the species from the MP clade. This finding agrees with the previous studies on the independent loss of $r p s l 2$, rps16, and $c l p P$ introns in the MP clade (Guo et al., 2007; Schwarz et al., 2015; Kaila et al., 2016). A correction has been made to Section: Discussion, Sub-section Evolutionary Pattern of PSV in the MP Clade.

Inserted CORRECTED paragraph: According to this study, with the exception of the loss of the $c l p P$ introns 1 and 2 in a single species of $S$. vestita (Phaseoleae) and the loss of $n d h A$ and $n d h B$ intron 1 in a single species of $L$. domingensis (Millettieae), two other introns (rps16 and rps12) have experienced multiple independent loss during the plastome evolution of the species from the MP clade. This finding agrees with the previous studies on the independent loss of rpsl2, rps16, and clpP introns in the MP clade (Guo et al., 2007; Schwarz et al., 2015; Kaila et al., 2016).

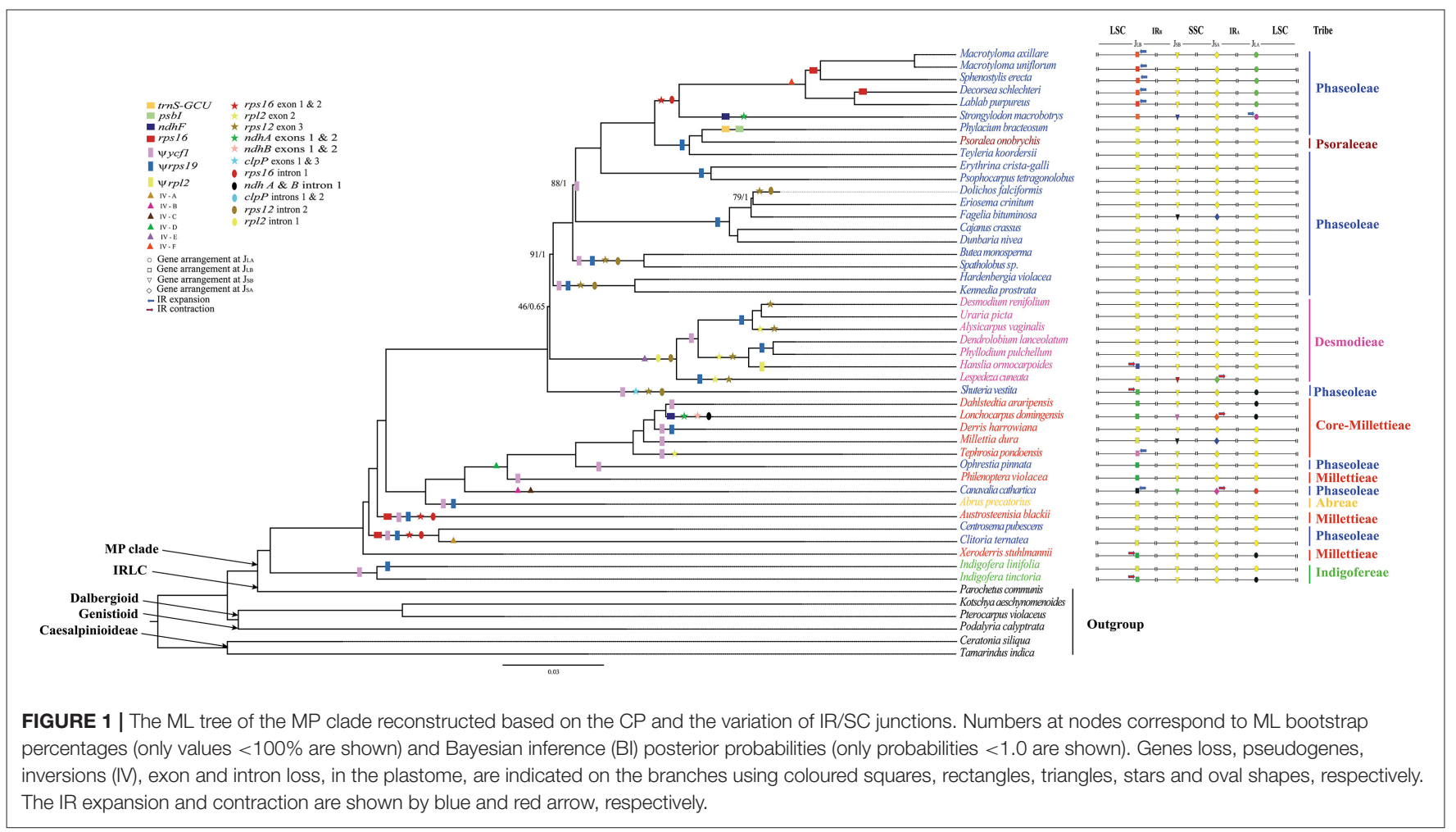



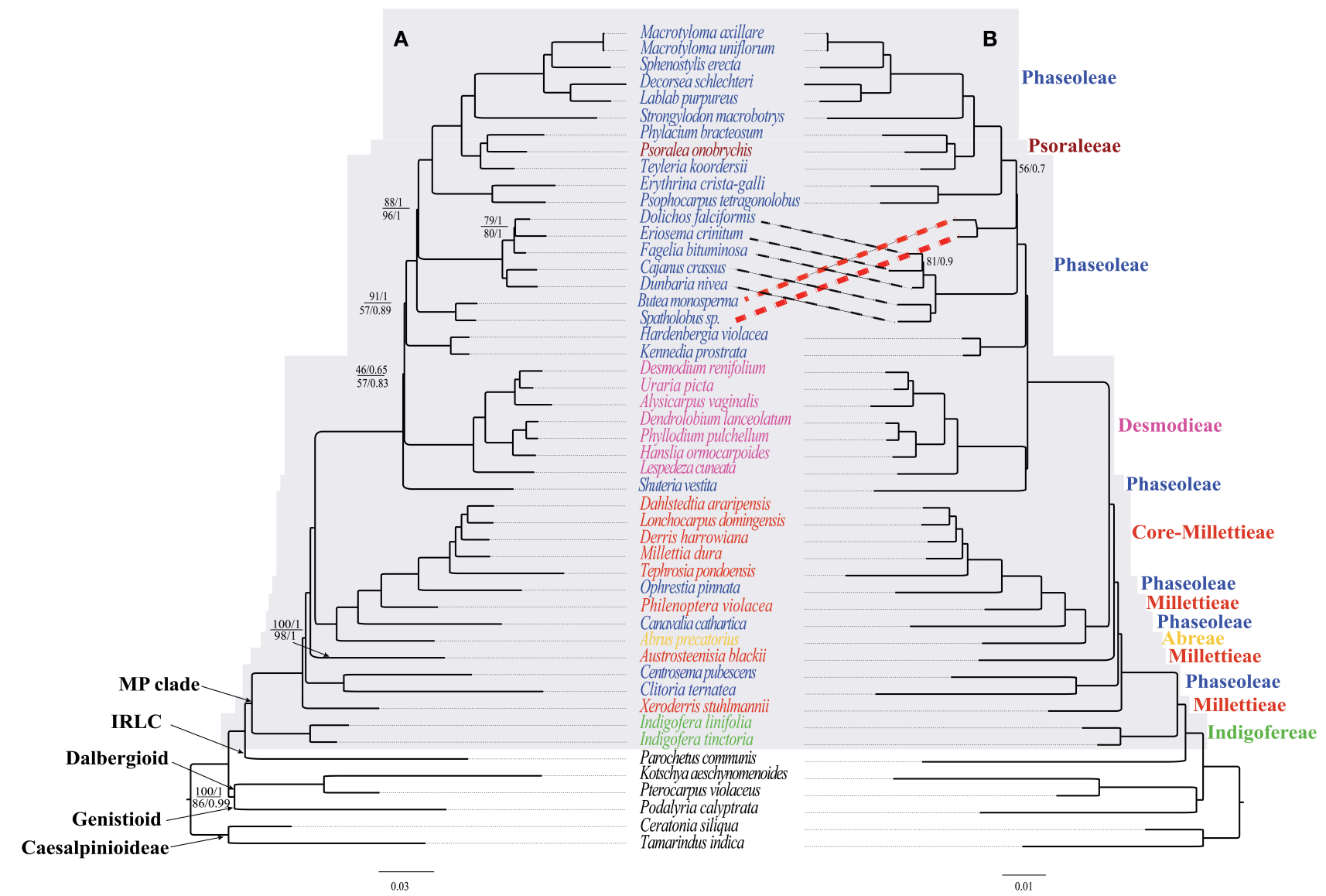

FIGURE 4 | The ML and BI phylogenetic relationships reconstructed for the MP clade. (A) CP and NCDs, and (B) CDs. Numbers at nodes correspond to ML bootstrap percentages (only values $<100 \%$ are shown) and Bayesian inference (BI) posterior probabilities (only probabilities $<1.0$ are shown). For (A), the values above and below the line represents support values for the CP and NCDs, respectively. The thick dotted lines indicate topology differences. The scale bar represents the mean nucleotide substitutions per site along the branch.

In the original article, there was an error: Desmodieae was supported as monophyletic group in previous studies (Bruneau et al., 1994; Doyle et al., 1997; Kajita et al., 2001; Stefanovic et al., 2009; Cardoso et al., 2013; de Queiroz et al., 2015; Egan et al., 2016), however this tribe was weakly supported as monophyletic by CDs but paraphyletic by CP and NCDs (Figure 4). A correction has been made to Section: Discussion, Sub-section Phylogenetic Relationships in the MP Clade.

Inserted CORRECTED paragraph: Desmodieae was supported as monophyletic group in previous studies (Bruneau et al., 1994; Doyle et al., 1997; Kajita et al., 2001; Stefanovic et al., 2009; Cardoso et al., 2013; de Queiroz et al., 2015; Egan et al., 2016), however this tribe was strongly supported as monophyletic by CDs but weakly supported by CP and NCDs (Figure 4).

In the original article, there was an error: Notably, our multilocus plastome data strongly supported $(\mathrm{BS}=100 \%, \mathrm{PP}=1)$ the evolutionary position of $S$. vestita within the tribe Desmodieae, in contrast with previous placement in the tribe Phaseoleae (Lackey et al., 1981; de Queiroz et al., 2015). Formerly, the genus Shuteria was included in the tribe Phaseoleae based on flower structures shared with core Phaseoleae species (e.g., Amphicarpaea Elliott ex Nutt., Cologania Kunth, and Dumasia DC., Lackey et al., 1981). It is noteworthy that a similar phylogenetic placement in the MP clade has been shown from analysis based on the single plastid region matK (de Queiroz et al., 2015). Therefore, our phylogeny supports the placement of $S$. vestita within the tribe Desmodieae. A correction has been made to Section: Discussion, Sub-section Phylogenetic Relationships in the MP Clade.

CORRECTED paragraph: Notably, our multi-locus plastome data suggested $(\mathrm{BS}=100 \%, \mathrm{PP}=1)$ the evolutionary position of $S$. vestita as sister to the tribe Desmodieae, in contrast with previous placement close to the subtribe Kennediinae of the tribe Phaseoleae (e.g., de Queiroz et al., 2015). Formerly, the genus Shuteria was included in the tribe Phaseoleae based on flower structures shared with core Phaseoleae species (e.g., Amphicarpaea Elliott ex Nutt., Cologania Kunth, and Dumasia DC., Lackey et al., 1981). It is noteworthy that a similar phylogenetic placement in the MP clade has been shown from analysis based on the single plastid region matK (de Queiroz et al., 2015). Therefore, our phylogeny supports the placement of $S$. vestita as sister to the tribe Desmodieae. Nevertheless, 
we expect that future phylogenetic studies would improve the understanding of the phylogenetic relationships of the genus Shuteria within the clade.

\section{REFERENCES}

Bruneau, A., Doyle, J. J., Doyle, J. A. (1994). "Phylogenetic relationships in Phaseoleae: evidence from chloroplast DNA restriction site characters," in Advances in legume systematics, Part 7. Eds. Crisp, M., Doyle, J. J. (Richmond, Surrey, UK: Royal Botanic Gardens, Kew), 309- 330.

Cardoso, D., Pennington, R. T., de Queiroz, L. P., Boatwright, J. S., Van Wyk, B. E., Wojciechowski, M. F., et al. (2013). Reconstructing the deepbranching relationships of the papilionoid legumes. S. Afr. J. Bot. 89, 58-75. doi: 10.1016/j.sajb.2013.05.001

de Queiroz, L. P., Pastore, J. F., Cardoso, D., Snak, C., de C Lima, A. L., Gagnon, E., et al. (2015). A multilocus phylogenetic analysis reveals the monophyly of a recircumscribed papilionoid legume tribe diocleae with well-supported generic relationships. Mol. Phylogenet. Evol. 90, 1-19. doi: 10.1016/j.ympev.2015.04.016

Doyle, J. J., Doyle, J. L., Ballenge, J. A., Dickson, E. E., Kajita, T., Ohashi, H. (1997). A phylogeny of the chloroplast gene rbcL in the Leguminosae: taxonomic correlations and insights into the evolution of nodulation. Am. J. Bot. 84, 541-554. doi: 10.2307/2446030

Egan, A. N., Vatanparast, M., Cagle, W. (2016). Parsing polyphyletic Pueraria: delimiting distinct evolutionary lineages through phylogeny. Mol. Phylogenet. Evol. 104, 44-59. doi: 10.1016/j.ympev.2016.08.001

Guo, X., Castillo-Ramírez, S., González, V., Bustos, P., Fernández-Vázquez, J. L., Santamaría, R. I., et al. (2007). Rapid evolutionary change of common bean (Phaseolus vulgaris L.) plastome, and the genomic diversification of legume chloroplasts. BMC Genom. 8, 228. doi: 10.1186/1471-2164-8-228
The authors apologize for these errors and state that this does not change the scientific conclusions of the article in any way.

The original article has been updated.

Kaila, T., Chaduvla, P. K., Saxena, S., Bahadur, K., Gahukar, S. J., Chaudhury, A., et al. (2016). Chloroplast Genome Sequence of Pigeonpea (Cajanus cajan (L.) Millspaugh) and Cajanus scarabaeoides (L.) Thouars: Genome organization and comparison with other legumes. Front. Plant Sci. 7, 1847. doi: $10.3389 /$ fpls.2016.01847

Kajita, T., Ohashi, H., Tateishi, Y., Bailey, C. D., Doyle, J. J. (2001). rbcL and legume phylogeny, with particular reference to Phaseoleae, Millettieae, and allies. Syst. Bot. 26, 15-536. doi: 10.1043/0363-6445-26.3.515

Lackey, J. A., Polhill, R. M., Raven, P. H. (1981). "Phaseoleae," in Advances in Legume Systematics, part 1 (UK: Royal Botanic Gardens, Kew), 301- 327.

Schwarz, E. N., Ruhlman, T. A., Sabir, J. S. M., Hajrah, N. H., Alharbi, N. S., AlMalki, A. L., et al. (2015). Plastid genome sequences of legumes reveal parallel inversions and multiple losses of $r p s 16$ in papilionoids. J. Syst. Evol. 53, 458-468. doi: $10.1111 /$ jse.12179

Stefanovic, S., Pfeil, B. E., Palmer, J. D., Doyle, J. J. (2009). Relationships among phaseoloid legumes based on sequences from eight chloroplast regions. Syst. Bot. 34, 115-128. doi: 10.1600/036364409787602221

Copyright (c) 2021 Oyebanji, Zhang, Chen and Yi. This is an open-access article distributed under the terms of the Creative Commons Attribution License (CC BY). The use, distribution or reproduction in other forums is permitted, provided the original author(s) and the copyright owner(s) are credited and that the original publication in this journal is cited, in accordance with accepted academic practice. No use, distribution or reproduction is permitted which does not comply with these terms. 